\title{
Insertion of a chimeric retrotransposon sequence in mouse Axin 1 locus causes metastable kinky tail phenotype
}

\author{
Zhuqing Wang ${ }^{1}$, Hayden McSwiggin', Simon J. Newkirk ${ }^{3}$, Yue Wang ${ }^{1}$, Daniel Oliver ${ }^{1}$, Chong Tang ${ }^{1}$, Sandy Lee', \\ Shawn Wang ${ }^{1}$, Shuiqiao Yuan ${ }^{1}$, Huili Zheng ${ }^{1}$, Ping $\mathrm{Ye}^{2,3}$, Wenfeng $\mathrm{An}^{3}$ and Wei Yan ${ }^{1,4,5^{*}}$
}

\begin{abstract}
Background: Transposable elements (TEs) make up $>50 \%$ of the human genome, and the majority of retrotransposon insertions are truncated and many are located in introns. However, the effects of retrotransposition on the host genes remain incompletely known.

Results: We report here that insertion of a chimeric L1 (CL1), but not IAP solo LTR, into intron 6 of Axin 1 using CRIPSR/ Cas9 induced the kinky tail phenotype with 80\% penetrance in heterozygous Axin ${ }^{C L 1}$ mice. Both penetrant (with kinky tails) and silent (without kinky tails) Axin ${ }^{c 1}$ mice, regardless of sex, could transmit the phenotype to subsequent generations with similar penetrance ( 80\%). Further analyses revealed that a longer Axin1 transcript isoform containing partial CL1targeted intron was present in penetrant, but absent in silent and wild type mice, and the production of this unique Axin 1 transcript appeared to correlate with altered levels of an activating histone modification, H3K9ac.

Conclusions: The mechanism for $A x i{ }^{c L 1}$ mice is different from those previously identified in mice with spontaneous retrotransposition of IAP, e.g., Axin ${ }^{F u}$ and $A^{w}$, both of which have been associated with DNA methylation changes. Our data suggest that Axin 1 locus is sensitive to genetic and epigenetic alteration by retrotransposons and thus, ideally suited for studying the effects of new retrotransposition events on target gene function in mice.
\end{abstract}

Keywords: Retrotransposon, CRISPR/Cas9, LINE-1, IAP, MaLR, Alternative splicing, Histone modification, DNA methylation, Epigenetic inheritance

\section{Background}

Transposable elements (TEs) make up $>50 \%$ of the human genome [1]. The vast majority of human TEs are retrotransposons, which replicate via a RNA-based process termed retrotransposition [2]. Based on sequence organization, retrotransposons are further classified into LTR (long terminal repeat) and non-LTR retrotransposons. LTR retrotransposons are also called endogenous retroviruses (ERVs), which display ongoing insertional activities in mice but not in humans [3]. Among them, mammalian apparent LTR retrotransposon (MaLR) elements are the most

\footnotetext{
* Correspondence: wyan@med.unr.edu

${ }^{1}$ Department of Physiology and Cell Biology, University of Nevada School of Medicine Center for Molecular Medicine, Room 207B 1664 North Virginia Street MS/0575, Reno, NV 89557, USA

${ }^{4}$ Department of Obstetrics and Gynecology, University of Nevada, Reno School of Medicine, Reno, NV 89557, USA

Full list of author information is available at the end of the article
}

abundant in both human and mouse genomes although they are no longer replicating [3-6]. On the other hand, IAP (intracisternal A-type particle) is one of a few LTR retrotransposon families that remain active in the mouse genome [3-6]. Non-LTR retrotransposons include long interspersed elements (LINEs) and short interspersed elements (SINEs). LINE-1 (L1) sequences are abundant ( $17 \%$ of the human genome) and have been identified as the only active and autonomous mobile element in the human genome [2, 3]. L1 consists of four components: a 5' untranslated region (UTR) that serves as a promoter, a 3' UTR containing a polyadenylation signal, an ORF1 (open reading frame 1) encoding an RNA binding protein with nucleic acid chaperone activity, and a conserved ORF2 protein that harbors reverse transcriptase and endonuclease activities [2]. In addition to self-mobilization, L1 proteins can also copy other RNAs into a new locus via

(c) The Author(s). 2019 Open Access This article is distributed under the terms of the Creative Commons Attribution 4.0 International License (http://creativecommons.org/licenses/by/4.0/), which permits unrestricted use, distribution, and 
several distinct pathways. SINEs, such as human Alu and SVA (SINE-VNTR-Alu) elements, hijack the L1 retrotransposition machinery and have successfully proliferated in the human genome [7-9]. Although not as efficient, nonTE transcripts can also be copied, forming processed pseudogenes $[10,11]$. The sequence downstream to a fulllength L1 can be mobilized to new locations via 3' transduction [12-15]. Indeed, a study of 244 cancer patients has revealed that almost $25 \%$ of patients have 3 ' transductions of L1 sequence [16]. Chimeric or hybrid sequences can be generated when L1 reverse transcriptase switches templates [17-19]. The vast majority of TEs in the genome are truncated or rearranged, leaving behind $3^{\prime}$ fragments of L1 s or single ("solo") LTRs of ERVs, in which ORFs critical for TE replication are lacking [2, 3, 20, 21]. Moreover, most of the TE insertions described to date in cancers are intronic or intergenic [22,23]. It remains to be investigated the extent to which TE insertions affect the expression of their host coding genes and genomic activities near the insertion sites.

It is difficult to study retrotransposition and its effects on gene expression because retrotransposon sequences are widespread in the genome and often integral parts of the introns of coding genes [22]. One approach is to follow the fate of de novo insertions that are launched from engineered donor L1 transgenes. In this regard, several cell and mouse models have been generated to study the effects of L1 retrotransposition by tagging human or mouse L1 s with intron-disrupted retrotransposition reporters [24-29]. This approach has indeed provided important insights into L1 retrotransposition activities in various cell lines and tissues [26-31]. In several cell types (e.g. mouse embryonic stem cells, rat neuronal progenitor cells, human embryonic carcinoma and other cancer derived cell lines), the newly integrated L1 s are efficiently silenced by epigenetic marks, such as DNA methylation, histone deacetylation or $\mathrm{H} 3 \mathrm{~K} 9 \mathrm{me} 3$ (H3 Lys9 trimethylation) [26-29]. In mouse models, when propagated through the germline, the retrotransposed sequences exert a graded influence on the flanking genomic sequences at the level of DNA methylation, creating "sloping shores" around the hypomethylated CpG island in germ cells [32]. A limitation of this approach is that both the site and the length of insertions are unpredictable. So it is impossible to compare the effect of different retrotransposon sequences on flanking genes. A complementary approach is to study the effect of spontaneous insertional mutagenesis by endogenous retrotransposition events in mice [33] and in humans [34]. However, these insertions are fixed, some insertions of retrotransposons in these loci may have no discernable phenotype, and therefore, the effects of these insertions remain to be elucidated. We sought to find some DNA loci that could result in discernable phenotypes to study the effects of L1 retrotransposition. Interestingly, two of most studied mouse models involve spontaneous LTR retrotransposon (e.g. IAP) insertions. The first is $A x i{ }^{F u}(A x i n-$ Fused) mice, in which a $5.1-\mathrm{kb}$ IAP retrotransposon is inserted in antisense orientation into intron 6 of Axin1, causing a kinky tail phenotype [35]. The second case is $A^{v y}$ (agouti viable yellow) mice, which show variable yellow agouti coat color phenotypes and is, similar to $\operatorname{Axin}^{F u}$, caused by a $5.1-\mathrm{kb}$ IAP insertion in antisense orientation into the pseudoexon 1A of agouti $(A)$ locus [36]. In both cases, DNA methylation levels of the IAP retrotransposon appear to inversely correlate with the severity of the phenotype. Additionally, both the DNA methylation patterns and phenotypes can be transmitted to subsequent generations in a metastable manner [37-40]. To study the effects of retrotransposed sequences, we attempted to generate mutant mice carrying either a shorter version of IAP LTR (e.g., a solo LTR) or a chimeric L1 (cL1) at the same sites in Axin1 and $A$ (agouti) loci using the CRISPR/Cas9 technology [4143]. Surprisingly, we failed to recapitulate the phenotypes when the solo LTR of IAP was inserted into the same two loci as those in the $A x i^{F u}$ and $A^{v y}$ mice. Of interest, we did observe kinky tail phenotype when the CL1 was inserted into intron 6 of Axin1 (termed $A x i n^{c L 1}$ ). Moreover, we found that the molecular mechanisms underlying the kinky tail phenotype were different between $A x i n^{C L 1}$ and $A x i{ }^{F u}$ mice.

\section{Results \\ Insertion of a chimeric L1, not the IAP solo LTR, into intron 6 of Axin 1 induced the kinky tail phenotype}

To test whether an IAP solo LTR can induce the kinky tail phenotype, we first inserted a 335 bp IAP solo LTR flanked by two loxP sites in reverse orientation into intron 6 of Axin1 using CRISPR/Cas9 (Additional file 1: Figure S1A and supplemental notes). The insert only contains the LTR of IAP identified in $A x i n^{F u}$ mice and has been shown to function as a cryptic promoter in those mice [38]. One founder was obtained, but with no kinky tail phenotype although both PCR-based genotyping and Sanger sequencing results showed that the IAP solo LTR was indeed inserted precisely (Additional file 1: Figure S1A). In $\operatorname{Axin}^{F u}$ mice, not all displayed the kinky tail phenotype; some have normal tails because of hypermethylated IAP [38]. When those silent $A x i n^{F u}$ mice are bred with wild type (WT) mice, a small proportion of their offspring do display the kinky tail phenotype [38]. Thus, a lack of the kinky tail phenotype in the founder obtained could be due to either that the IAP solo LTR alone could not induce the kinky tail phenotype, or that the insert got silenced in founder mice. To test the two possibilities, we crossed the Axin $^{I A P}$ founder with WT mice, but none of $>20 A x i n 1^{+/ I A P}$ F1 mice showed the kinky tail phenotype, suggesting that the IAP solo LTR insertion does not disrupt Axin1 gene expression and thus, induces no kinky tail phenotype. Similarly, no variable 
yellow agouti coat color phenotype was found in either of the founder (F0) or $21 \mathrm{~F} 1$ mice when an antisense IAP solo LTR, which is the same as that identified in $A^{v y}$ mice [37, $39,40]$, was inserted into the $A$ (agouti) locus (Additional file 1: Figure S1B and supplemental notes).

Next, we tested whether insertion of other repetitive sequences can induce the kinky tail phenotype. We generated a repetitive sequence, called chimeric L1 (cL1) herein, consisting of a partial Orf2 of L1 and an LTR of MaLR, and inserted it into intron 6 of Axin1 using the CRISPR/Cas9 (Fig. $1 \mathrm{a}$ and $\mathrm{d}$ and Additional file 1: supplemental notes). To represent a retrotransposed sequence, we also included $6 \mathrm{bp}$ target site duplications (TSDs) and $44 \mathrm{bp} 5^{\prime}$ extra nucleotides in the cL1 donor construct (Fig. 1d and Additional file 1: supplemental notes). We chose to use this specific chimeric L1 to mimic retrotransposition in vivo for the following reasons: First, such a chimeric sequence may result from template switching or transduction during retrotransposition, which is a pervasive phenomenon in both human and mouse genomes [17-19]. Second, the $762 \mathrm{bp}$ Orf2 of L1 (Fig. 1d and Additional file 1: supplemental notes), which harbors a partial Z-motif and a partial reverse transcriptase domain, is highly conserved among different L1 families [44-46]. When aligning the Orf2 sequence against the mm10 genome with BLAT [47], one exact match was found on chromosome 3:76892981-76,893,742 and 70 other hits showed $>80 \%$ sequence identity (Additional file 2: Table S1). Moreover, the MaLR elements are the most abundant LTR retrotransposon sequences in both human and mouse genomes [3]. When aligning the LTR of the MaLR to the mouse genome mm10, 20 perfect matches were found and over 200 other hits showed >96\% sequence identity (Additional file 3: Table S2). Therefore, insertion of the two conserved regions (L1 Orf2 and MaLR LTR) of TEs into the genome allows for studying the combined genetic/epigenetic impact at this locus. Finally, both TE fragments have no retrotransposition capability, which is further confirmed by our assays for DNA copy number variation (Additional file 1: Figure S1C).

We obtained 3 founders (F0) carrying the cL1 insertion, which was confirmed by Sanger sequencing of the long-range PCR products containing the full-length cL1 (Fig. 1d). One of the three founders showed a strong kinky tail phenotype, while the other two had normal tails, despite the same genotype $\left(A x i n 1^{+/ c L 1}\right)$. By further breeding the F0s with WT mice, we obtained F1 heterozygous mice. Intercrossing F1 heterozygous mice produced WT, heterozygous and homozygous F2 mice at the Mendelian ratio (Fig. 1d). All homozygous (Axin1 ${ }^{c L 1 / c L 1}$ ) mice showed kinky tails and also displayed neuronal abnormalities characterized by motor discordances (e.g., spinning with shaky heads and imbalance), whereas $\sim 80 \%$ of the heterozygous $\left(A x i n 1^{+/ c L 1}\right)$ mice showed the kinky tail phenotype and the remaining heterozygous mice had normal tails (Fig. $1 \mathrm{~b}$ and c). These results suggest that a chimeric L1/MaLR sequence, rather than IAP solo LTR, can cause the kinky tail phenotype once inserted into intron 6 of Axin 1 in mice.

\section{Stable transmission of the kinky tail phenotype with a fixed penetrance across multiple generations} $A x i^{F u}\left(A x i n 1^{+F u}\right)$ mice showed kinky tails with highly variable severity, and the penetrant $A x i{ }^{F u}$ mice (with strong or mild kinky tails) produced more penetrant offspring compared to those silent ones (without kinky tails) [38]. This phenotype can be transmitted to the next generation in a metastable manner, and the phenotypic variability correlates with the methylation status of the IAP retrotransposed into intron 6 in the offspring [38]. To examine whether the kinky tail phenotype induced by cL1 also displays a similar variability in phenotypic severity, we conducted breeding experiments to test the transmission of the phenotype through either paternal or maternal germline across three generations. Heterozygous $A x i^{c L 1}$ $\left(A x i n 1^{+/ c L 1}\right)$ penetrant and silent male F2 s were bred with WT females, and $\sim 80 \%$ of the $A x i n^{c L 1}$ offspring (F3 s) were penetrant mice (Fig. 2a). Further breeding of the penetrant and silent F3 and F4 Axin ${ }^{c L 1}$ males and females with WT controls led to F4 and F5 Axin ${ }^{c L 1}$ offspring displaying the kinky tail phenotype with similar penetrance $(\sim 80 \%)$ (Fig. $2 \mathrm{a}$ ). The phenotypic penetrance stayed the same (at $~ 80 \%$ ) across all three generations when the cL1 insertion was propagated through either the paternal or the maternal germline (Fig. 1c and Fig. 2). Among the penetrant $A_{x i n}{ }^{c L 1}$ mice, the ones with stronger kinky tails accounted for $70 \%$ across all three generations, regardless of paternal or maternal inheritance (Fig. 2a and b), suggesting the kinky tail phenotype can be stably inherited transgenerationally as long as the cL1 insertion exists.

\section{The kinky tail phenotype in Axin ${ }^{C L 1}$ mice is caused by an aberrantly spliced Axin 1 transcript}

Retrotransposons inserted into the genome have been shown to act as a cryptic promoter, a terminator, and/or to induce alternative splicing $[4,29,38,48-53]$. First, we performed dual luciferase reporter assays to test whether cL1 could function as a promoter (Additional file 1: Figure S2). Different parts of cL1 were amplified and used to replace the SV40 early promoter of Renilla luciferase reporter $(R l u c)$ in the psiCHECK-2 vector. Promoter activity was detected in the antisense MaLR solo LTR, but not in other fragments, including the cL1 that we used to generate Axin ${ }^{c L 1}$ mice (Additional file 1: Figure S2), indicating that cL1 does not function as a cryptic promoter in the context of the reporter construct. To test whether aberrant transcripts are produced, we performed Northern blot analyses with probes specific to Axin1 exons 5, 6, 7 and 8 (Fig. 3a). Indeed, we found that a longer transcript was detected exclusively in penetrant mice (Fig. 3a). Consistent with 


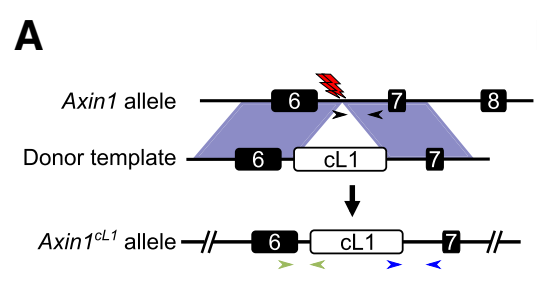

C

Paternal inheritance Maternal inheritance

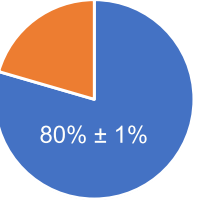

Axin ${ }^{C L 1}$ Penetant

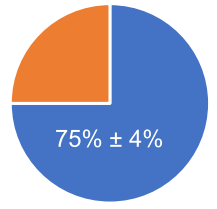

Axin $^{c L 1}$ Silent
B

Phenotype

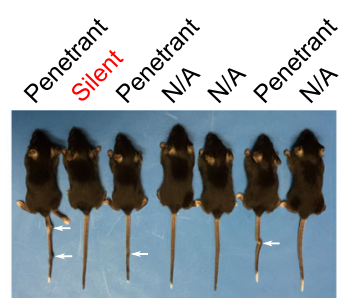

Genotype

Animal \# M 958959960961962963964 WT H2O

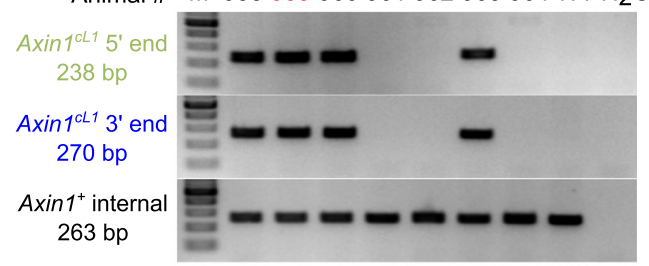

D

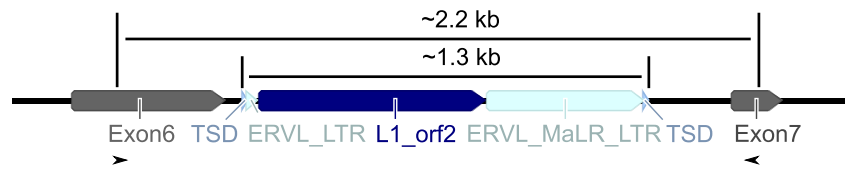

96979899100101102103 WT H2O
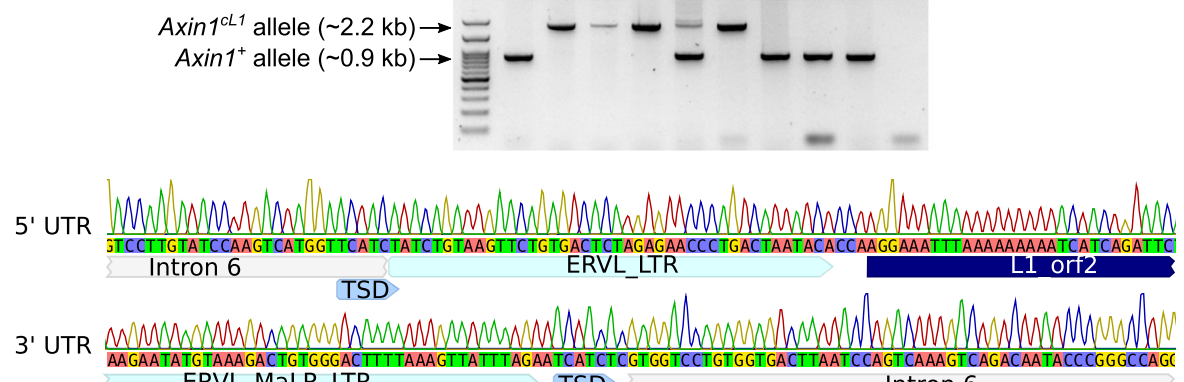
ERVL MaLR LTR

TSD

Intron 6

Fig. 1 Generation of Axin ${ }^{\complement L 1}$ mice using CRISPR/Cas9 and phenotypic characterization. a Schematics showing the strategy for generating Axin ${ }^{\complement l 1}$ mice. The red lightning bolt represents the gRNAs used to target the reverse strands of the genomic DNA. The black arrows show the position of internal primers in the Axin $1^{+}$allele, whereas the blue and the light green arrows indicate those for amplifying the $5^{\prime}$ and $3^{\prime}$ ends of the Axin $7^{\not L}$ allele, respectively. The expected size of PCR products is indicated in the same color in the lower panels of $\mathbf{b}$. $\mathbf{b}$ Image of a representative litter of seven F5 mice derived from a F4 silent $A_{x i n}{ }^{C l 1}\left(A x i n 1^{+/ C l 1}\right.$ ) female mouse bred with a WT male, including three penetrant (white arrows pointing to the kinked regions in the tails), one silent $A x$ in $^{c L 1}$ mouse and three WT (Axin ${ }^{+/+}$) littermates (Upper panel). Genotyping results of these mice are shown in lower panels and the positions of the three sets of primers used are marked in a. c Pie charts showing the distribution of penetrant (with kinky tails) vs. silent (without kinky tails) Axin ${ }^{\text {Cl. }}$ $\left(A x i n 1^{+/ \mathcal{L} l}\right)$ mice in an outbreeding scheme $\left(A x i n 1^{+/ C L 1} \times W T\right)$ across three generations. Data are represented as means \pm SEM $(n=353$ for paternal transgenerational inheritance, and $n=425$ for maternal transgenerational inheritance). $\mathbf{d}$ Confirmation of CL1 insertion into intron 6 of Axin 1. Long-range PCR was used to amplify fragments derived from $\operatorname{Axin}^{c{ }^{L 1}}(\sim 2.2 \mathrm{~kb})$ and WT $(\sim 0.9 \mathrm{~kb})$ alleles (upper and middle panels), and the PCR products were sequenced to confirm the successful CL1 insertion in intron 6 of Axin 1(lower panels). TSD, target site duplications; ERVL_LTR, LTR of MT2_Mm in ERVL family (5' extra nucleotide); L1_orf2, orf2 of Lx2 in L1 family; ERVL_MaLR_LTR, LTR of MT_int in ERVL_MaLR family, serving as the 5' extra nucleotides

Northern blot results, our RT-PCR analyses using primers specific to exons 5 and 8 also found an alternative splicing event in penetrant, but not in silent $A$ xin $^{c L 1}$ mice (Fig. 3b). Sanger sequencing of the longer isoform revealed that part of the CL1 (L1-MaLR) sequence was included in the aberrant Axin1 transcript, which was spliced at the canonical GU-AG splicing site, in penetrant mice (Fig. 3d and Additional file 1: supplemental notes). We further designed specific primers for the alternatively spliced Axin 1 transcript. qPCR confirmed that the alternative spliced Axin1 transcript is exclusively expressed in penetrant $A_{x i n}{ }^{c L 1}$ mice (Fig. 3c). Taken together, these data strongly suggest that the kinky tail phenotype in the $A x i n^{c L 1}$ mice is induced by an aberrantly spliced Axin 1 transcript due to intron retention of CL1.

\section{Altered H3K9ac modification, rather than DNA methylation changes, correlates with the aberrantly spliced Axin 1 mRNA}

Despite the same genotype $\left(A x i n 1^{+/ c L 1}\right)$, only $\sim 80 \%$ of $A x{ }^{2}{ }^{c L 1}$ mice express the aberrant transcripts with partial cL1 retention. Therefore, epigenetic mechanisms 
A
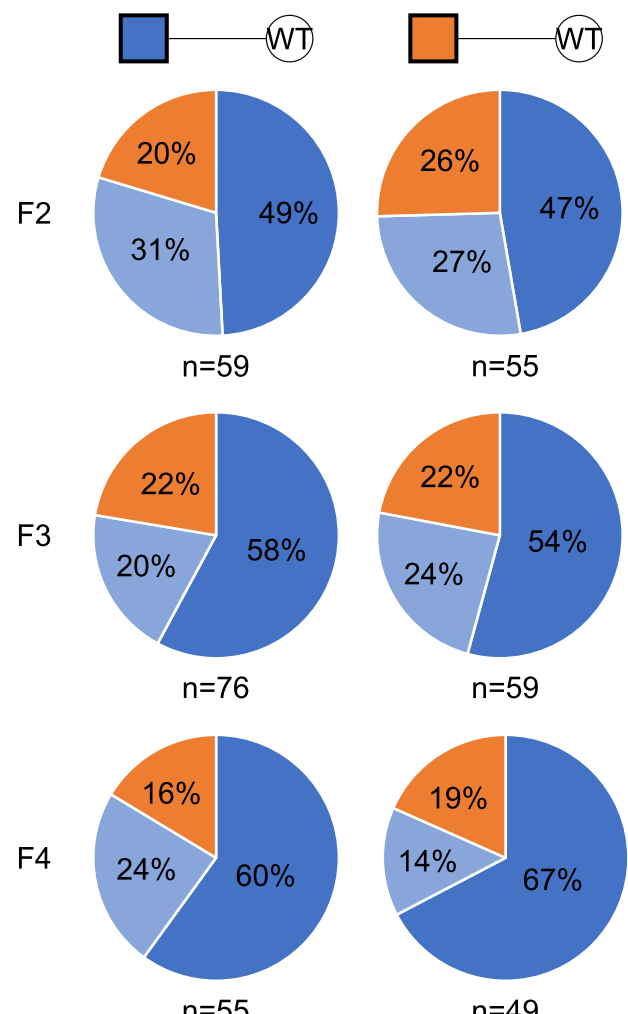

$n=55$

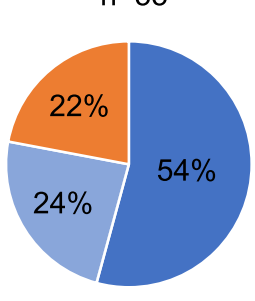

$n=59$

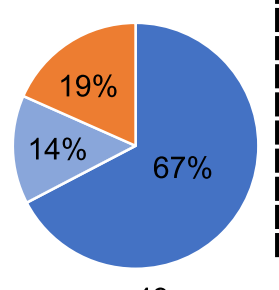

$n=49$
B
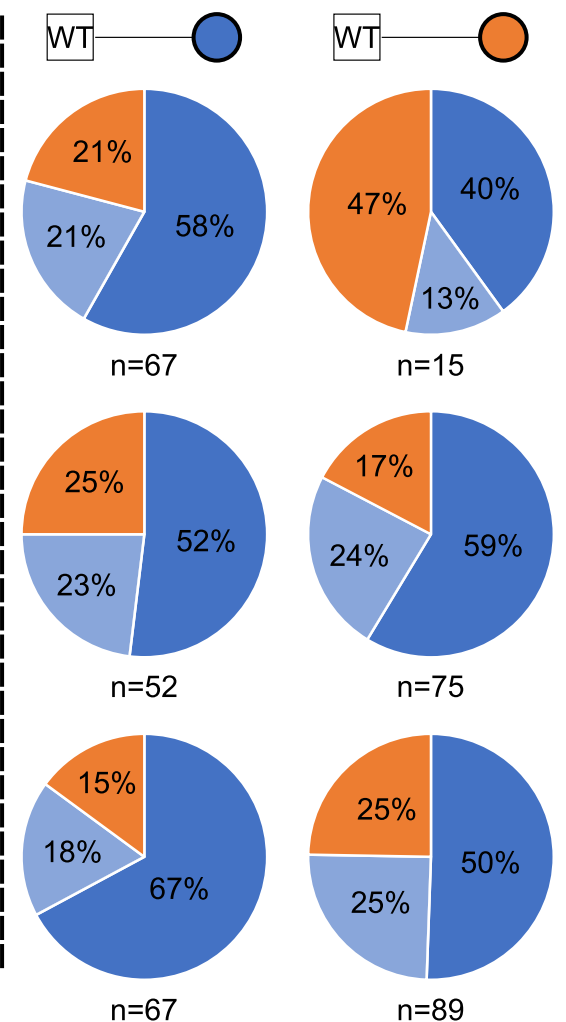

$\mathrm{n}=89$

penetrant male $\square$ silent male

penetrant female

silent female

strong

mild

silent

Fig. 2 Transgenerational inheritance of the kinky tail phenotype in $A x i{ }^{c L 1}\left(A x i n 1^{+/ C L 1}\right)$ mice. a Paternal transgenerational inheritance of the kinky tail phenotype among $A x i n^{c L 1}$ mice. Male penetrant (left panel) and silent (right panel) Axin ${ }^{c L 1}$ mice were bred with wild type (WT) females, and the percentage of strong (dark blue) or mild (light blue) kinky and silent (orange) Axin ${ }^{\complement L 1}$ offspring, as well as the number of mice counted are indicated (Note that WT pups were excluded from the analyses). b Maternal transgenerational inheritance of the kinky tail phenotype among Axin $^{\subset L l}$ mice. Female penetrant (left panel) and silent (right panel) Axin ${ }^{C L 1}$ mice were bred WT females, and the percentage of strong (dark blue) or mild (light blue) kinky and silent (orange) Axin ${ }^{C L 1}$ offspring, as well as the number of mice counted are indicated (Note that WT pups were excluded from the analyses)

are likely involved. Given that DNA methylation and histone modifications of the IAP LTR sequences in $A x i{ }^{F u}$ mice have been correlated with the variable phenotypic severity [38,54], we first examined DNA methylation of CL1 and its flanking regions in both penetrant and silent $A x$ in $^{c L 1}$ mice. Surprisingly, bisulfite sequencing showed that DNA methylation patterns were not significantly altered between penetrant and silent $A x$ in $^{c L 1}$ mice (Additional file 1: Figure S3 A and B). Additionally, no major changes in DNA methylation were found between the two groups by both methylated DNA immunoprecipitation (MeDIP) of 5-methylcytosine $(5 \mathrm{mC})$ and $\mathrm{Hhal}$ restriction enzyme (RE) digestion, which cleaves unmethylated GCGC site specifically, followed by qPCR (MeDIP-qPCR and RE-qPCR) (Additional file 1: Figure S3C). Taken together, these results suggest that the aberrant alternative splicing of Axin1 transcript is not due to altered DNA methylation. Given that histone modifications (e.g. H3K9ac) affect alternative splicing [55-57], and H3K9ac and H4K20me3 marks have been associated with proper splicing of intron 6 of Axin1 [54], we performed chromatin immunoprecipitation followed by qPCR (ChIP-qPCR) to examine H3K9ac levels (Fig. 4 a-c) at the Axin $^{c L 1}$ locus. Levels of H3K9ac, a histone mark for open chromatin structure, were much higher at the cL1 insertion site in the silent than in the penetrant mice (Fig. $4 \mathrm{a}$ and $\mathrm{b}$ ). These data suggest that a reduction in $\mathrm{H} 3 \mathrm{~K} 9 \mathrm{ac}$ levels on the $\mathrm{CL} 1$ insertion site and its neighboring regions may affect splicing, leading to the production of a longer transcript containing CL1 (Fig. $4 \mathrm{~d}$ ). 
A
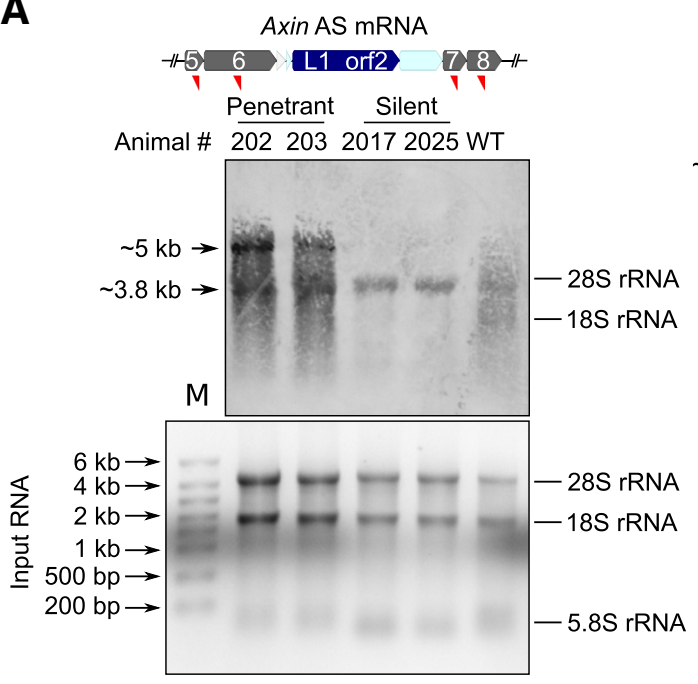

D

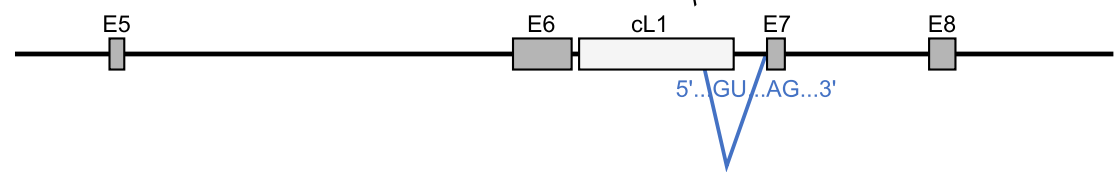

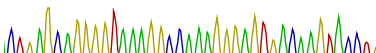

5 ' end

B

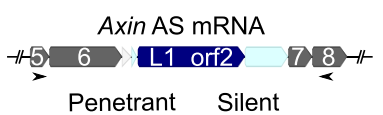

Penetrant Silent

Animal \# M 20220320172025 WT $\mathrm{H}_{2} \mathrm{O}$

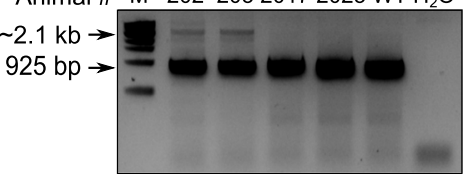

C

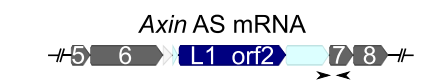

$\left.\sum_{\bar{\alpha}}{ }^{4}\right] \cdot \operatorname{Axin}^{c L 1}$ AS mRNA
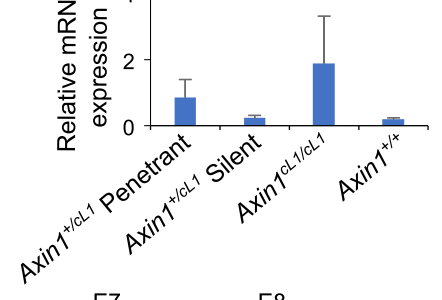

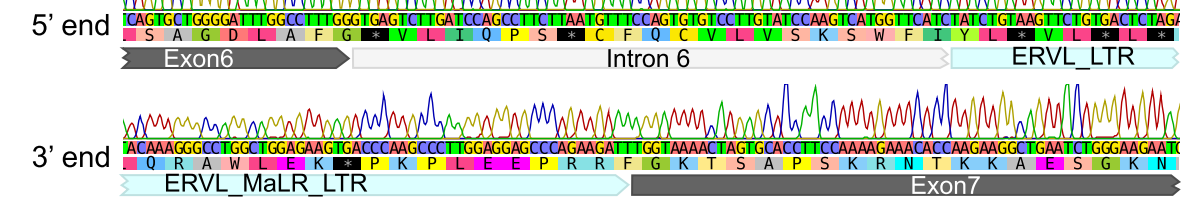

Fig. 3 A longer Axin 1 transcript isoform containing partial $C L 1$ is exclusively expressed in the penetrant Axin ${ }^{c L 1}$ mice. a A representative Northern blot showing that the wild type transcript $(\sim 3.8 \mathrm{~kb})$ was detected in Axin ${ }^{C L 1}$ mice, both penetrant and silent, as well as wild type mice, whereas a longer transcript $(\sim 5 \mathrm{~kb})$ was present only in penetrant Axin ${ }^{C L 1}$ mice (middle panel). Red triangles indicate the relative positions of the probes used in the upper panel, and the total RNA inputs are shown in the lower panel. $\mathbf{b}$ RT-PCR detection of the longer transcript isoform unique to penetrant Axin ${ }^{\text {CL1 }}$ mice. A pair of primers encompassing exons 5 and 8 (arrows in the upper panel) was used for PCR detection of WT (925 bp) and CL1-Containing ( $\sim 2.1$ kb) transcripts (lower panel). c qPCR quantification of the longer transcript isoform unique to penetrant $A x i n^{C L 1}$ and homozygous $A x i n 1^{C L 1 / C L 1}$ mice. Data are presented as means \pm SEM, $n=3$. $\mathbf{d}$ Schematic illustration of the alternative splicing event leading to the production of a longer transcript isoform unique to penetrant $A x i n^{C L 1}$ mice (upper panel), as supported by the Sanger sequencing results (lower panel)

\section{Discussion}

Mutant mice with variable yellow agouti coat color and kinky tail phenotypes were first reported 82 and 57 years ago, respectively $[58,59]$. It was not until $\sim 20$ years ago that these phenotypes were correlated with spontaneous retrotransposition of IAPs in the mouse $A$ (agouti) and Axin1 loci, respectively $[35,36]$. However, validation by inserting the IAP into these loci to recapitulate the phenotypes in different strains of mice has not been reported. Moreover, identification of a locus that is sensitive to retrotransposition, and tends to produce a visually discernable phenotype (e.g., kinky tails, coat color changes, etc.) as a result of functional disruptions would be ideal for investigating the effects of retrotransposition in vivo. To this end, we generated a number of mouse lines by inserting various repetitive sequences into exactly the same genomic location in either A(agouti) or Axin1 locus as that reported in
$A^{v y}$ or $A x i n^{F u}$ mice [37-40]. Interestingly, we found that insertion of IAP solo LTR induced no phenotypes, whereas insertion of a composite cL1 sequence into Axin1 locus caused the kinky tail phenotype, which can be transmitted faithfully across multiple generations. These findings indicate that intronic retrotransposition events do not necessarily cause disruptions in the host genes leading to discernable phenotypes and that the effects of retrotransposition depend on sequence context and organization. Indeed, previous studies have shown that heterozygotes of 3 spontaneous mutations in Axin1 gene, including $A x i n^{F u}$ $\left(A x i n^{\text {Fused }}\right), A x i n^{K i}\left(A x i n^{K i n k y}\right)$ and $A x i n^{K b}\left(A x i n^{K n o b b y}\right)$, all display the kinked tail phenotype, yet heterozygotes of a transgenic line called $A x i n^{T g 1}$ showed no phenotype [35]. Furthermore, $A x$ in $^{F u}$ homozygotes are viable, whereas $A x i n^{K i}, A x i n^{K b}$ and $A x i n^{T g 1}$ homozygotes die around embryonic days $8-10$ [35]. It is highly likely that the variable 


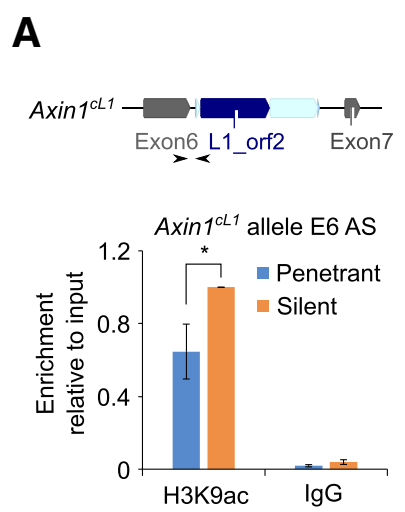

D

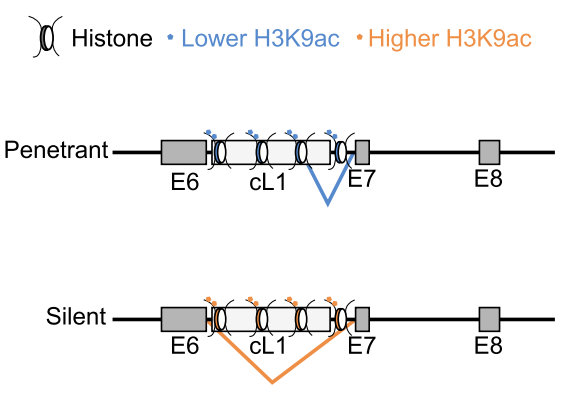

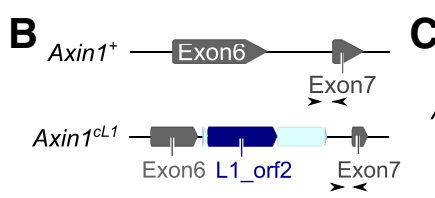

C
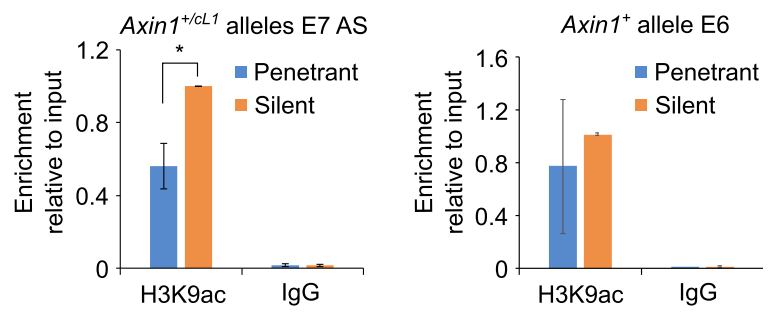

E

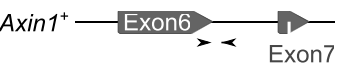

i DNA methylation Histone modification

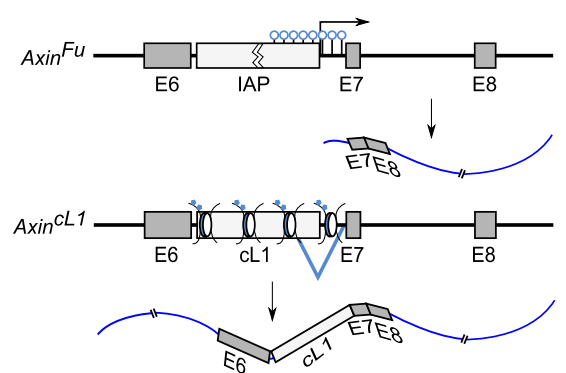

Fig. 4 Reduced H3K9ac levels at the $C L 1$ insertion site in penetrant Axin ${ }^{c L 1}$ mice. a ChIP-qPCR analyses of H3K9ac levels using primers specific to the exon 6 splicing site of the Axin $1^{c L l}$ allele. Arrows indicate relative locations of the primers used for ChIP-qPCR analyses (upper panel). Data are presented as means $\pm \mathrm{SEM}, n=3,{ }^{*} p<0.05$. $\mathbf{b}$ ChIP-qPCR analyses of H3K9ac levels using primers specific to the exon 7 splicing site of the Axin $7^{\llcorner L l}$ and Axin $1^{+}$alleles. Arrows indicate relative locations of the primers used for ChIP-qPCR analyses (upper panel). Data are presented as means $\pm S E M, n=3,{ }^{*} p<$ 0.05. c ChIP-qPCR analyses of H3K9ac levels using primers specific to the exon 6 splicing site of the $A x i n 1^{+}$allele. Arrows indicate relative locations of the primers used for ChIP-qPCR analyses (upper panel). Data are presented as means \pm SEM, $n=3$. d Schematic illustration showing the effect of reduced H3K9ac levels on splicing. Briefly, higher H3K9ac levels ensure correct splicing, which excludes CL1 from the transcript, whereas with lower H3K9ac levels, the $\mathrm{CL} 1$ tends to be retained and included in the transcript. e Comparison of the molecular mechanisms underlying the kinky tail phenotype between $\mathrm{Axin}^{F u}$ and $A \mathrm{Axin}^{\mathrm{CL} l}$ mice. The kinky tail phenotype in $A x{ }^{F u}$ mice results from a shorter transcript isoform initiated from intron 6, and the phenotypic severity is inversely correlated with DNA methylation status, whereas the kinky tail phenotype in $A x i n^{\complement L 1}$ mice is caused by a longer transcript isoform with $\mathrm{CL} 1$ intron retention, and the penetrance of the phenotype is fixed at 70-80\%, and inversely correlated with H3K9ac levels at the CL1 insertion site

phenotypes among these strains reflect the positional effects of different insertions, e.g., the $A x i n^{T g 1}$ mice contain a $\sim 600$ bp transgene replacing exon 2, whereas $A x i n^{F u}$ and $A x i{ }^{K b}$ contain an IAP insertion in intron 6 and exon 7, respectively [35]. The lack of phenotype in mice carrying an insertion of IAP solo LTR into intron 6 of Axin1 or pseudo exon $1 \mathrm{~A}$ of agouti $(A)$ loci is consistent with a recent report [21] showing that IAP LTR rarely displays promoter activity in vivo. Given that the IAP solo LTR sequence used was a part of the full-length IAP identified in $A^{v y}$ and $A x i n^{F u}$ mice, the negative finding hints that other parts of the full-length IAP sequences may contain certain hidden features (e.g., subtle sequence variations and/or RNA modifications), which are required for functional disruption of the host genes and consequently the induction of the kinky tail or variable yellow coat color phenotypes.

Although insertions of full-length IAP or CL1 into intron 6 of Axin1 locus all induced the kinky tail phenotype, the underlying mechanisms appear to be different. In $A x i n^{F u}$, IAP insertion into intron 6 compromises Axin1 gene expression by producing a truncated transcript, which is inversely correlated to DNA methylation status [38]. In contrast, in our $\mathrm{Axin}^{c L 1}$ mice, while the inserted cL1 sequence displays neither promoter activities in vitro nor DNA methylation changes in vivo, production of the aberrant transcript resulting from the retention of CL1 appears to correlate with significantly reduced levels of H3K9ac. Supporting our findings, reduced H3K9ac has been shown to cause alternative exon retention in Ncam (Neural cell adhesion molecule) due to decreased RNA polymerase processivity [56, 57]. Moreover, H3K9ac is also significantly more enriched in the IAP LTR of the $A x i n^{F u}$ locus in embryos sired by penetrant males than those by silent males [54]. A recent study [53] reports that MaLR LTRs function as splicing donors rather than splicing acceptors, which is consistent with our data showing that the MaLR 
LTR in the cL1 serves as a splicing donor. While associations between H3K9ac levels and aberrant splicing have been established [55-57], the underlying mechanism remains elusive. In $A x i n 1^{c L 1}$ mice, the longer splicing variant containing partial chimeric L1 sequence possesses several premature termination codons (PTCs), which are well known to cause transcript degradation via the nonsense mRNA decay (NMD) pathway [60-62]. However, our Northern blot results revealed that the longer transcript, which is unique to the penetrant $A x i n^{c L 1}$ mice, was nearly as abundant as the shorter wild-type one, suggesting that the splicing variant does not undergo NMD-mediated degradation. Therefore, it is highly likely that the longer splicing variant is translated into a mutant form of AXIN1 with a truncated $\mathrm{C}$ terminus lacking DIX domain, as compared to wild-type AXIN1. Unfortunately, we have not been able to identify a commercial antibody that could detect wild-type AXIN1 correctly ( $92 \mathrm{kD}$ protein). Production of good AXIN1 antibodies and generation of a mouse model over-expressing the splicing variant/mutant AXIN1 lacking DIX domain would provide the ultimate evidence supporting the cause-effect relationship between the splicing variant/mutant AXIN1 without DIX domain and the kinky tail phenotype in the future. Together, our data suggest that the Axin1 locus is sensitive to genetic and epigenetic alterations caused by retrotransposition and thus, can serve as an ideal genomic location for studying the effects of retrotransposition on host gene expression and activities of nearby genome. With advancement of the CRISPR/Cas9 technology, TEs of interest can easily be inserted into the Axin1 locus and the effects of various TEs on Axin1 and nearby genome can be analyzed in vivo.

Transgenerational epigenetic inheritance of the variable yellow agouti coat color and kinky tail phenotypes in $A^{v y}$ and $A x i n^{F u}$ mice is of great interest although the underlying mechanism remains elusive. In $A x i n^{F u}$ mice, the variable DNA methylation levels of IAP inversely correlate with the severities of the kinky tail phenotype, and penetrant mice tend to produce more penetrant offspring [38]. DNA methylation undergoes two waves of reprogramming during fertilization and germ line specification [63] and IAP seems to be resistant to these reprogramming events [38], which may explain the transgenerational inheritance of the phenotypes in $A^{v y}$ and $A x i n^{F u}$ mice. However, in $A x i n^{c L 1}$ mice, the kinky tail phenotype occurs as long as the cL1 insertion is present, and the penetrance is fixed at $\sim 70-80 \%$. Therefore, the kinky phenotype most likely represent a genetic phenomenon at first glance, and the stable inheritance of this phenotype across multiple generations in $\mathrm{Axin}^{c L 1}$ mice appears to be a simple genetic, rather than an epigenetic, transmission, i.e., a cL1 insertional mutation causes the phenotype in each generation. However, partial penetrance $(70-80 \%)$ of the phenotype can only be explained by an epigenetic mechanism. Our data have linked H3K9ac to the aberrant splicing events, but it remains unknown how such an alteration in histone modifications causes aberrant splicing at a rate of $70-80 \%$ rather than $100 \%$.

In summary, we show that insertion of a chimeric L1 into intron 6 of Axin 1 affects histone modification patterns on CL1 and its neighboring regions, leading to the production of an aberrant Axin1 transcript correlated with the kinky tail phenotype. This mechanism is different from that previously identified in mice with spontaneous IAP retrotransposition (e.g., $A x i^{F u}$ and $A^{v y}$ mice), which results from DNA methylation changes. Axin1 locus may serve as an ideal genomic location for studying the effects of new retrotransposition events on target gene function in mice in vivo.

\section{Conclusions}

Despite their widespread distribution in the human genome, effects of retrotransposons on their host genes and nearby genome have not been exhaustively investigated in vivo. Here, we show that insertion of a chimeric L1 into intron 6 of Axin1 locus in mice could induce the kinky tail phenotype due to the production of an aberrantly spliced transcript isoform, which is associated with altered histone modifications rather than DNA methylation changes. Together with previous reports, our data strongly suggest that Axin1 is an ideal locus for studying the effects of retrotransposition on host gene expression and nearby genome activities in vivo.

\section{Methods}

\section{Animal use and care}

All the mice used in this study were on C57Bl/6 J background, and housed under specific pathogen-free conditions in a temperature- and humidity- controlled animal facility at the University of Nevada, Reno.

\section{Generation of knock-in mice and breeding scheme} gRNAs were designed using the MIT website (https:// zlab.bio/guide-design-resources) and cloned into pX330 plasmid as previously described [42, 43]. The gRNAs were in vitro transcribed using HiScribe ${ }^{\mathrm{ma}}$ T7 High Yield RNA Synthesis Kit (E2040S, NEB) and purified using RNA Clean \& Concentrator ${ }^{\text {Tit }}-5$ (R1013, Zymo Research). Cas9 mRNA was purchased from TriLink BioTechnologies (L7606). The IAP LTR and the chimeric L1 were synthesized by IDT, and two homology arms $(\sim 1 \mathrm{~kb})$ flanking the gRNA cutting sites of $A$ or $A x i n 1$ locus were amplified by $\mathrm{Q} 5^{\circ}$ Hot Start High-Fidelity $2 \mathrm{X}$ Master Mix (M0494S, NEB) from mouse tail genomic DNA. Donor DNA templates that contain homology arms and the IAP LTR or the chimeric L1 were generated with NEBuilder ${ }^{\circ}$ HiFi DNA Assembly Master Mix (E2621L, NEB). 
The gRNAs, Cas9 mRNA and donor DNA template were microinjected into mice zygotes of $\mathrm{FVB} / \mathrm{NJ} \times$ C57BL/6 J background for Axin1 locus knock-in and C57BL/6 J for $A$ locus knock-in. The genomic DNA of founder mice from tail tips or ear snips were extracted for PCR-based genotyping. Founder mice were outcrossed with C57BL/6 J WT to obtain heterozygous F1 $\left(A x i^{+/ I A P}\right.$ or $\left.A x i^{+/ C L 1}\right)$. For $A^{I A P}, \mathrm{~F} 1 \mathrm{~s}$ were outcrossed with C57BL/6 J WT to obtain heterozygous F2 s, and coat color was recorded. For Axin ${ }^{I A P}, \mathrm{~F} 1 \mathrm{~s}$ were outcrossed with C57BL/6 J WT to obtain heterozygous F2 s, and tail phenotype was examined. For $A x{ }^{c L 1}, \mathrm{~F} 1 \mathrm{~s}$ were outcrossed with C57BL/6 J WT to obtain heterozygous F2 s, and tail phenotype was recorded. Penetrant and silent heterozygous F2s, F3 s, and F4s were further outcrossed with C57BL/6 J WT to obtain the breeding data across multiple generations. Primers used for all the constructs are listed in Additional file 4: Table S3.

\section{Mouse genotyping}

Mouse tail or ear snip samples were lysed in a lysis buffer containing $40 \mathrm{mM} \mathrm{NaOH}$ (221465, Sigma Aldrich) and 0.2 mM EDTA (46-034-CI, Corning) for $1 \mathrm{~h}$ at $95^{\circ} \mathrm{C}$, followed by neutralization with the same volume of the neutralizing buffer containing $40 \mathrm{mM}$ Tris- $\mathrm{HCl}$ (15567027, Thermo Fisher Scientific). PCR-based genotyping of the Axin ${ }^{c L 1}$, $A x$ in $^{I A P}$ and $A^{I A P}$ was conducted using the GoTaq Green master mix (M7123, Promega) or Platinum ${ }^{\text {Tx }}$ SuperFi $^{\text {in }}$ Green PCR Master Mix (12359010, Thermo Fisher Scientific). Primers used for genotyping are listed in Additional file 4: Table S3.

\section{Dual luciferase assay}

Different fragments of the repetitive sequences were amplified from donor templates and then used to replace the SV40 early promotor that drives the expression of the Renilla luciferase-coding sequence in the psiCHECK-2 plasmid (C8021, Promega). HEK293 cells were transfected with psiCHECK-2 containing the different fragments from the repetitive sequences using Lipofectamine 2000 (11668019, Thermo Fisher Scientific) in a 24-well cell culture plate (CLS3527-100EA, Corning). After 24 h, cells were lysed and used for the Dual Luciferase Assay (E1910, Promega) according to the manufacturer's instructions. The psiCHECK-2 and psiCHECK-2 vectors with deletion of the SV40 early promotor of the Renilla luciferase-coding sequence were used as positive and negative controls, respectively. Renilla luciferase signals were normalized to Firefly luciferase signals to correct the transfection efficiency. Primers used for all the constructs are listed in Additional file 4: Table S3.

\section{DNA, RNA extraction and CDNA synthesis}

DNA and RNA were extracted from kidneys and tail snips from penetrant and silent mice using the Quick-DNA Plus
Kits (D4074, Zymo Research) and mirVana miRNA Isolation Kit (AM1560, Thermo Fisher Scientific), respectively, according to the manufacturer's instructions. Briefly, kidney or tail samples were homogenized in $600 \mu \mathrm{L}$ of Lysis/ Binding Buffer with homogenizer (D1000, Benchmark), followed by centrifugation to remove cell debris. The supernatant was passed through a column, in which the genomic DNA was retained, whereas the RNA got eluted. For genomic DNA extraction, the column containing genomic DNA was treated with a genomic lysis buffer at room temperature for $10 \mathrm{~min}$, followed by washing with a DNA Pre-Wash Buffer once and a g-DNA Wash Buffer twice. The genomic DNA was eluted with nuclease-free water and stored at $-80^{\circ} \mathrm{C}$ for further use. For RNA extraction, $60 \mu \mathrm{L}$ of miRNA Homogenate Additive was added into the flow-through followed by incubation on ice for $10 \mathrm{~min}$. The mixture was subjected to Phenol: Chloroform RNA extraction, and total RNA was isolated according to the manufacturer's instructions. cDNA synthesis was performed using SuperScript II Reverse Transcriptase (18064014, Thermo Fisher Scientific) with random primers. qPCR and long-range PCR were performed using the Fast SYBR Green Master Mix (4385612, Thermo Fisher Scientific) and PrimeSTAR GXL DNA Polymerase (R050B, TaKaRa), respectively. Primers used for qPCR and long-range PCR are listed in Additional file 4: Table S3.

\section{Bisulfite sequencing}

Genomic DNA samples were bisulfite-converted using the EZ DNA Methylation-Gold ${ }^{\mathrm{me}}$ Kit (D5005, Zymo Research). PCR was performed using the TaKaRa EpiTaq ${ }^{\text {Tx }}$ HS enzyme (for bisulfite-treated DNA) (R110B, TaKaRa), which is more tolerant to dUTP-containing templates, with $\mathrm{Tm}$ at $55^{\circ} \mathrm{C}$ for 40 cycles. PCR products were ligated into the pGEM ${ }^{\circ}$ - T Easy Vector (A1360, Promega) for Sanger sequencing. Primers used for bisulfite sequencing are listed in Additional file 4: Table S3.

\section{Methylated DNA immunoprecipitation-qPCR (MeDIP- qPCR)}

MeDIP was performed using a Methylated DNA immunoprecipitation kit (ab117133, Abcam) according to instructions of the manufacturer. In brief, $100 \mu \mathrm{L}$ of the antibody buffer and $1 \mu \mathrm{L}$ anti-5-methylcytosine or mouse IgG antibody were added into strip wells and incubated at room temperature for $1 \mathrm{~h}$. During the incubation, tail genomic DNA was sheared by a focused-ultrasonicator (M220, Covaris) in the reaction buffer. The sheared DNA ranged between 200 and $1000 \mathrm{bp}$ in size and was denatured at 95 ${ }^{\circ} \mathrm{C}$ for $2 \mathrm{~min}$ followed by incubation on ice. An aliquot of $5 \mu \mathrm{L}$ of the denatured DNA was used as input DNA. The strip wells bound with antibody were washed with $150 \mu \mathrm{L}$ of the antibody buffer once and $150 \mu \mathrm{L}$ of the wash buffer once, followed by incubation with the sheared DNA at 
room temperature for $2 \mathrm{~h}$. Then the strip wells were washed with the wash buffer three times. The antibodyenriched DNA was eluted with a DNA release buffer containing proteinase $\mathrm{K}$ and purified with columns. qPCR was performed to identify DNA methylation levels. Primers used for MeDIP-qPCR are listed in Additional file 4: Table S3.

\section{Northern blot}

Northern blot analyses were performed using a NorthernMax Kit (AM1940, Thermo Fisher Scientific) and a Biotin Chromogenic Detection Kit (K0662, Thermo Fisher Scientific) following the manufacturer's instructions. Briefly, RNA extracted from kidney was mixed with 3 volumes of a formaldehyde-containing loading dye followed by denaturation at $65^{\circ} \mathrm{C}$ for $15 \mathrm{~min}$. The denatured RNA was the fractionated through $1 \times$ MOPS Gel Running Buffer ( $1 \%$ denaturing gel with a voltage of $140 \mathrm{~V}$ for $30 \mathrm{~min}$ ). Then the RNA was transferred onto a BrightStar-Plus Positively Charged Nylon Membrane (AM10100, Thermo Fisher Scientific) using Novex $^{\text {tm }}$ Semi-Dry Blotter (SD1000, Thermo Fisher Scientific) in 1× TBE buffer with a voltage of $20 \mathrm{~V}$ for $30 \mathrm{~min}$. After transfer, the membrane was rinsed $1 \times$ Gel Running Buffer, then crosslinked in Spectrolinker ${ }^{\text {Tx }}$ XL-1500 UV crosslinker (Spectronics Corporation) followed by baking at $80^{\circ} \mathrm{C}$ for $15 \mathrm{~min}$. The crosslinked membrane was prehybridized at $65^{\circ} \mathrm{C}$ in a preheated ULTRAhyb Buffer in a roller bottle in a hybridization oven at $42{ }^{\circ} \mathrm{C}$ for $30 \mathrm{~min}$, followed by incubation with $10 \mathrm{pM}$ biotinylated probe (IDT) in the ULTRAhyb Buffer at $42{ }^{\circ} \mathrm{C}$ overnight. After rinsing with $1 \times$ Blocking/Washing Buffer for $5 \mathrm{~min}$ three times at room temperature, the membrane was blocked with $1 \times$ Blocking Buffer for $30 \mathrm{~min}$ in a shaker at room temperature. Following blocking, the membrane was incubated with Streptavidin-AP conjugate for $1 \mathrm{~h}$ at room temperature, then washed with $1 \times$ Blocking/Washing Buffer for 5 min three times and 1× detection buffer for $10 \mathrm{~min}$. Then the membrane was incubated with freshly prepared NBT/BCIP Substrate Solution at room temperature in the dark. $2 \mathrm{~h}$ later, the reaction was stopped by rinsing with double deionized water. Probes used for Northern blot are listed in Additional file 4: Table S3.

\section{Chromatin immunoprecipitation followed by quantitative PCR (ChIP-qPCR)}

ChIP-qPCR was performed as previously described [64]. Briefly, tail snips were lysed on ice for $30 \mathrm{~min}$ in $600 \mu \mathrm{l}$ of buffer 1 plus detergents [15 mM Tris- $\mathrm{HCl}$ (pH 7.5) (1556 7027, Thermo Fisher Scientific), $60 \mathrm{mM} \mathrm{KCl} \mathrm{(P217-500,}$ Fisher Scientific), $5 \mathrm{mM} \mathrm{MgCl} 2$ (BP214-500, Fisher Scientific) and $0.1 \mathrm{mM}$ EGTA (O2783-100, Fisher Scientific), $0.3 \mathrm{M}$ sucrose (freshly added) (0335-5KG, Amresco), 10 mM DTT (freshly added) (GE17-1318-02, GE Healthcare), 0.25\% (volume/volume) NP-40 (NP40S-500ML, Sigma
Aldrich) and $0.5 \%$ (weight/volume) sodium deoxycholate (freshly prepared) (D6750-100G, Sigma Aldrich)]. Then $600 \mu \mathrm{l}$ of MNase buffer [85 mM Tris- $\mathrm{HCl}, \mathrm{pH} 7.5,3 \mathrm{mM}$ $\mathrm{MgCl}_{2}, 2 \mathrm{mM} \mathrm{CaCl} 2$ (C7902-500G, Sigma Aldrich) and 0.3 $M$ sucrose (freshly added)] was added into the lysed solution. The mixture was aliquoted into $200 \mu \mathrm{l}$ per tube to obtain sufficient digestion, followed by Micrococcal Nuclease (M0247S, NEB) digestion at $37^{\circ} \mathrm{C}$ in a thermomixer for 5 min and then terminated by adding $2 \mathrm{ul}$ of $0.5 \mathrm{M}$ EDTA (46-034-CI, Corning) and incubation on ice for $5 \mathrm{~min}$. The digested sample was then centrifuged at $15,000 \times \mathrm{g}$ for 10 min at room temperature to remove cell debris, followed by adding protease inhibitors to the chromatin. $200 \mu$ lof the mixture was saved as input DNA. After preclearing of the chromatin with blocked protein G beads (10004D, Thermo Fisher Scientific), $3 \mu \mathrm{l}$ of H3K9ac antibody (ab4441, Abcam) was added into the precleared chromatin and incubated at $4{ }^{\circ} \mathrm{C}$ overnight. Then the chromatin was incubated with blocked protein $\mathrm{G}$ beads at $4{ }^{\circ} \mathrm{C}$ for $4 \mathrm{~h}$, followed by washing with wash buffer A $(50 \mathrm{mM}$ Tris- $\mathrm{HCl}$ (pH 7.5), $10 \mathrm{mM}$ EDTA and $75 \mathrm{mM} \mathrm{NaCl}$ (BP358-10, Fisher Scientific)) once and wash buffer B $(50 \mathrm{mM}$ Tris- $\mathrm{HCl}$ (pH 7.5), $10 \mathrm{mM}$ EDTA and $125 \mathrm{mM} \mathrm{NaCl}$ ) twice. Then the chromatin was eluted by resuspending in $150 \mu \mathrm{l}$ of elution buffer (1\% (weight/volume) SDS (L4509-500G, Sigma Aldrich) in TE) at $25^{\circ} \mathrm{C}$ in a thermomixer twice. The eluted chromatin was then subjected to RNase A (EN0531, Thermo Fisher Scientific) and proteinase $\mathrm{K}$ (P8107S, NEB) digestion followed by phenol/chloroform extraction of DNA. The pull-down DNA and input DNA were used for qPCR using the Fast SYBR Green Master Mix (4385612, Thermo Fisher Scientific). Primers used for ChIP-qPCR are listed in Additional file 4: Table S3.

\section{Statistical analysis}

All data were presented as mean \pm SEM, and statistical differences were assessed by the Two-sample $t$ test unless stated otherwise. $p<0.05$ was considered as significant differences.

\section{Additional files}

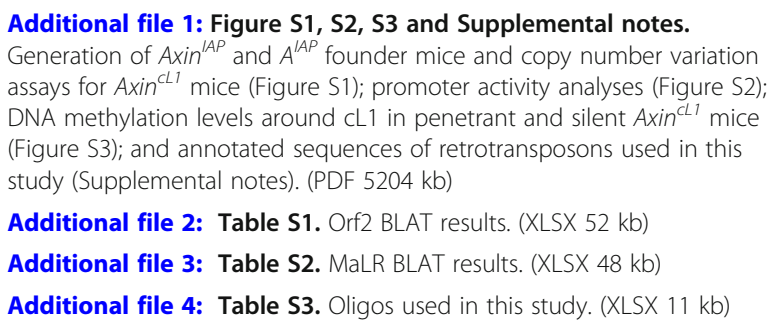

Additional file 2: Table S1. Orf2 BLAT results. (XLSX $52 \mathrm{~kb}$ )

Additional file 3: Table S2. MaLR BLAT results. (XLSX $48 \mathrm{~kb}$ )

Additional file 4: Table S3. Oligos used in this study. (XLSX $11 \mathrm{~kb}$ )

\section{Abbreviations}

5mC: 5-methylcytosine; $A^{v y}$ : Agouti viable yellow; $A x$ in $^{c L 1}$ : Axin $1^{+/ C L 1}$;

Axin Fu. Axin Fused: Axin Kb: Axin Knobby: Axin Ki: Axin Kinky; BLAT: BLAST-like alignment tool; Cas9: CRISPR associated protein 9; ChIP: Chromatin 
immunoprecipitation; CL1: Chimeric L1; CRIPSR: Clustered regularly interspaced short palindromic repeats; ERV: Endogenous retroviruse; IAP: Intracisternal A-type particle; L1: LINE-1; LINE: Long interspersed element; LTR: Long terminal repeat; MaLR: Mammalian apparent LTR retrotransposon; MeDIP: Methylated DNA immunoprecipitation; ORF: Open reading frame; qPCR: Quantitative PCR; RE: Restriction enzyme; SINE: Short interspersed elements; SVA: SINE-VNTR-Alu; TE: Transposable element; TSDs: Target site duplications; UTR: Untranslated region; WT: Wild type

\section{Acknowledgements}

Not applicable.

\section{Funding}

This work was supported by grants from the NIH (P30GM110767, HD071736 and HD085506 to WY; R21HD080143 and P50GM107632 to WA), the Markl Faculty Scholar Fund (to WA) and the Templeton Foundation (PID: 50183 to WY)

\section{Availability of data and materials}

All data generated or analyzed during this study are included in this published article and its supplementary information files.

\section{Authors' contributions}

WY and ZW designed the research. ZW, HM, SJN, YW, DO, CT, SL, SW, SY, PY and $\mathrm{HZ}$ performed the experiments. WA contributed reagents and protocols, and edited the manuscript; all analyzed the data; WY and ZW wrote the manuscript. All authors read and approved the final manuscript.

\section{Ethics approval and consent to participate}

The animal use protocol was approved by the Institutional Animal Care and Use Committee (IACUC) of the University of Nevada, Reno (protocol number 00494).

\section{Consent for publication}

Not applicable.

\section{Competing interests}

The authors declare that they have no competing interests.

\section{Publisher's Note}

Springer Nature remains neutral with regard to jurisdictional claims in published maps and institutional affiliations.

\section{Author details}

${ }^{1}$ Department of Physiology and Cell Biology, University of Nevada School of Medicine Center for Molecular Medicine, Room 207B 1664 North Virginia Street MS/0575, Reno, NV 89557, USA. ${ }^{2}$ Avera McKennan Hospital and University Health Center, Sioux Falls, SD 57108, USA. ${ }^{3}$ Department of Pharmaceutical Sciences, South Dakota State University, Brookings, SD 57007, USA. ${ }^{4}$ Department of Obstetrics and Gynecology, University of Nevada, Reno School of Medicine, Reno, NV 89557, USA. ${ }^{5}$ Department of Biology, University of Nevada, Reno, Reno, NV 89557, USA.

\section{Received: 19 January 2019 Accepted: 21 April 2019}

\section{Published online: 03 May 2019}

\section{References}

1. de Koning AP, Gu W, Castoe TA, Batzer MA, Pollock DD. Repetitive elements may comprise over two-thirds of the human genome. PLoS Genet. 2011; 7(12):e1002384.

2. Kazazian HH Jr, Moran JV. Mobile DNA in health and disease. N Engl J Med. 2017;377(4):361-70.

3. Mager DL, Stoye JP. Mammalian endogenous retroviruses. Microbiol Spectr. 2015;3(1):MDNA3-0009-2014.

4. Akagi K, Li J, Stephens RM, Volfovsky N, Symer DE. Extensive variation between inbred mouse strains due to endogenous $L 1$ retrotransposition. Genome Res. 2008;18(6):869-80.

5. Nellaker C, Keane TM, Yalcin B, Wong K, Agam A, Belgard TG, Flint J, Adams DJ, Frankel WN, Ponting CP. The genomic landscape shaped by selection on transposable elements across 18 mouse strains. Genome Biol. 2012;13(6):R45.
6. Mouse Genome Sequencing C, Waterston RH, Lindblad-Toh K, Birney E, Rogers J, Abril JF, Agarwal P, Agarwala R, Ainscough R, Alexandersson M, et al. Initial sequencing and comparative analysis of the mouse genome. Nature. 2002:420(6915):520-62.

7. Dewannieux M, Esnault C, Heidmann T. LINE-mediated retrotransposition of marked Alu sequences. Nat Genet. 2003:35(1):41-8.

8. Hancks DC, Goodier JL, Mandal PK, Cheung LE, Kazazian HH Jr. Retrotransposition of marked SVA elements by human L1s in cultured cells. Hum Mol Genet. 2011;20(17):3386-400.

9. Raiz J, Damert A, Chira S, Held U, Klawitter S, Hamdorf M, Lower J, Stratling WH, Lower R, Schumann GG. The non-autonomous retrotransposon SVA is trans-mobilized by the human LINE-1 protein machinery. Nucleic Acids Res. 2012;40(4):1666-83.

10. Esnault C, Maestre J, Heidmann T. Human LINE retrotransposons generate processed pseudogenes. Nat Genet. 2000;24(4):363-7.

11. Wei W, Gilbert N, Ooi SL, Lawler JF, Ostertag EM, Kazazian HH, Boeke JD, Moran JV. Human L1 retrotransposition: cis preference versus trans complementation. Mol Cell Biol. 2001;21(4):1429-39.

12. Moran JV, DeBerardinis RJ, Kazazian HH Jr. Exon shuffling by L1 retrotransposition. Science. 1999;283(5407):1530-4.

13. Pickeral OK, Makalowski W, Boguski MS, Boeke JD. Frequent human genomic DNA transduction driven by LINE-1 retrotransposition. Genome Res. 2000;10(4):411-5.

14. Goodier JL, Ostertag EM, Kazazian HH Jr. Transduction of 3'-flanking sequences is common in L1 retrotransposition. Hum Mol Genet. 2000;9(4):653-7.

15. Solyom S, Ewing AD, Hancks DC, Takeshima Y, Awano H, Matsuo M Kazazian HH Jr. Pathogenic orphan transduction created by a nonreference LINE-1 retrotransposon. Hum Mutat. 2012;33(2):369-71.

16. Tubio JMC, Li Y, Ju YS, Martincorena I, Cooke SL, Tojo M, Gundem G, Pipinikas CP, Zamora J, Raine K, et al. Mobile DNA in cancer. Extensive transduction of nonrepetitive DNA mediated by L1 retrotransposition in cancer genomes. Science. 2014;345(6196):1251343.

17. Buzdin A, Ustyugova S, Gogvadze E, Vinogradova T, Lebedev Y, Sverdlov E. A new family of chimeric retrotranscripts formed by a full copy of U6 small nuclear RNA fused to the 3' terminus of I1. Genomics. 2002;80(4):402-6.

18. Symer DE, Connelly C, Szak ST, Caputo EM, Cost GJ, Parmigiani G, Boeke JD. Human 11 retrotransposition is associated with genetic instability in vivo. Cell. 2002;110(3):327-38

19. Gilbert N, Lutz-Prigge S, Moran JV. Genomic deletions created upon LINE-1 retrotransposition. Cell. 2002;110(3):315-25.

20. Thompson PJ, Macfarlan TS, Lorincz MC. Long terminal repeats: from parasitic elements to building blocks of the transcriptional regulatory repertoire. Mol Cell. 2016;62(5):766-76.

21. Kazachenka A, Bertozzi TM, Sjoberg-Herrera MK, Walker N, Gardner J Gunning R, Pahita E, Adams S, Adams D, Ferguson-Smith AC. Identification, characterization, and heritability of murine metastable Epialleles: implications for non-genetic inheritance. Cell. 2018;175(5): 1259-71.e13.

22. Burns KH. Transposable elements in cancer. Nat Rev Cancer. 2017:17(7):415-24.

23. Elbarbary RA, Lucas BA, Maquat LE. Retrotransposons as regulators of gene expression. Science. 2016;351(6274):aac7247.

24. Ostertag EM, DeBerardinis RJ, Goodier JL, Zhang Y, Yang N, Gerton GL, Kazazian HH Jr. A mouse model of human L1 retrotransposition. Nat Genet. 2002;32(4):655-60

25. An W, Han JS, Wheelan SJ, Davis ES, Coombes CE, Ye P, Triplett C, Boeke JD. Active retrotransposition by a synthetic $\mathrm{L} 1$ element in mice. Proc Natl Acad Sci U S A. 2006;103(49):18662-7.

26. Muotri AR, Chu VT, Marchetto MC, Deng W, Moran JV, Gage FH. Somatic mosaicism in neuronal precursor cells mediated by $\mathrm{L} 1$ retrotransposition. Nature. 2005;435(7044):903-10.

27. Garcia-Perez JL, Morell M, Scheys JO, Kulpa DA, Morell S, Carter CC, Hammer GD, Collins KL, O'Shea KS, Menendez P, et al. Epigenetic silencing of engineered $L 1$ retrotransposition events in human embryonic carcinoma cells. Nature. 2010;466(7307):769-73.

28. Kannan M, Li J, Fritz SE, Husarek KE, Sanford JC, Sullivan TL, Tiwary PK, An W, Boeke JD, Symer DE. Dynamic silencing of somatic L1 retrotransposon insertions reflects the developmental and cellular contexts of their genomic integration. Mob DNA. 2017:8:8.

29. Liu N, Lee CH, Swigut T, Grow E, Gu B, Bassik MC, Wysocka J. Selective silencing of euchromatic L1s revealed by genome-wide screens for L1 regulators. Nature. 2018;553(7687):228-32. 
30. Kano H, Godoy I, Courtney C, Vetter MR, Gerton GL, Ostertag EM, Kazazian $\mathrm{HH}$ Jr. L1 retrotransposition occurs mainly in embryogenesis and creates somatic mosaicism. Genes Dev. 2009;23(11):1303-12.

31. Newkirk SJ, Lee S, Grandi FC, Gaysinskaya V, Rosser JM, Vanden Berg N, Hogarth CA, Marchetto MCN, Muotri AR, Griswold MD, et al. Intact piRNA pathway prevents L1 mobilization in male meiosis. Proc Natl Acad Sci U S A. 2017;114(28):E5635-E44.

32. Grandi FC, Rosser JM, Newkirk SJ, Yin J, Jiang X, Xing Z, Whitmore L, Bashir S, Ivics Z, Izsvak Z, et al. Retrotransposition creates sloping shores: a graded influence of hypomethylated CpG islands on flanking CpG sites. Genome Res. 2015;25(8):1135-46.

33. Maksakova IA, Romanish MT, Gagnier L, Dunn CA, van de Lagemaat LN, Mager DL. Retroviral elements and their hosts: insertional mutagenesis in the mouse germ line. PLoS Genet. 2006;2(1):e2.

34. Hancks DC, Kazazian HH Jr. Roles for retrotransposon insertions in human disease. Mob DNA. 2016;7:9.

35. Vasicek TJ, Zeng L, Guan XJ, Zhang T, Costantini F, Tilghman SM. Two dominant mutations in the mouse fused gene are the result of transposon insertions. Genetics. 1997;147(2):777-86.

36. Duhl DM, Vrieling H, Miller KA, Wolff GL, Barsh GS. Neomorphic agouti mutations in obese yellow mice. Nat Genet. 1994;8(1):59-65.

37. Morgan HD, Sutherland HG, Martin DI, Whitelaw E. Epigenetic inheritance at the agouti locus in the mouse. Nat Genet. 1999;23(3):314-8.

38. Rakyan VK, Chong S, Champ ME, Cuthbert PC, Morgan HD, Luu KV, Whitelaw E. Transgenerational inheritance of epigenetic states at the murine Axin (Fu) allele occurs after maternal and paternal transmission. Proc Natl Acad Sci U S A. 2003;100(5):2538-43.

39. Waterland RA, Jirtle RL. Transposable elements: targets for early nutritional effects on epigenetic gene regulation. Mol Cell Biol. 2003;23(15):5293-300.

40. Rosenfeld CS, Sieli PT, Warzak DA, Ellersieck MR, Pennington KA, Roberts RM Maternal exposure to bisphenol a and genistein has minimal effect on a (vy)/a offspring coat color but favors birth of agouti over nonagouti mice. Proc Natl Acad Sci U S A. 2013;110(2):537-42.

41. Cong L, Ran FA, Cox D, Lin SL, Barretto R, Habib N, Hsu PD, Wu XB, Jiang WY, Marraffini LA, et al. Multiplex Genome engineering using CRISPR/Cas systems. Science. 2013;339(6121):819-23.

42. Wang Z, Lee S, Oliver D, Yuan S, Tang C, Wang Y, Zheng H, Yan W. Prps111, a testis-specific gene, is dispensable for mouse spermatogenesis. Mol Reprod Dev. 2018;85(10):802-4.

43. Oliver D, Yuan S, McSwiggin H, Yan W. Pervasive genotypic mosaicism in founder mice derived from Genome editing through pronuclear injection. PLoS One. 2015;10(6):e0129457.

44. Sookdeo A, Hepp CM, McClure MA, Boissinot S. Revisiting the evolution of mouse LINE-1 in the genomic era. Mob DNA. 2013;4(1):3.

45. Mathias SL, Scott AF, Kazazian HH Jr, Boeke JD, Gabriel A. Reverse transcriptase encoded by a human transposable element. Science. 1991; 254(5039):1808-10.

46. Clements AP, Singer MF. The human LINE-1 reverse transcriptase:effect of deletions outside the common reverse transcriptase domain. Nucleic Acids Res. 1998;26(15):3528-35.

47. Kent WJ. BLAT--the BLAST-like alignment tool. Genome Res. 2002;12(4):656-64.

48. Goodier JL, Kazazian HH Jr. Retrotransposons revisited: the restraint and rehabilitation of parasites. Cell. 2008;135(1):23-35.

49. Erwin JA, Marchetto MC, Gage FH. Mobile DNA elements in the generation of diversity and complexity in the brain. Nat Rev Neurosci. 2014;15(8):497-506

50. Chen J, Rattner A, Nathans J. Effects of L1 retrotransposon insertion on transcript processing, localization and accumulation: lessons from the retinal degeneration 7 mouse and implications for the genomic ecology of L1 elements. Hum Mol Genet. 2006;15(13):2146-56.

51. Li J, Kannan M, Trivett AL, Liao H, Wu X, Akagi K, Symer DE. An antisense promoter in mouse $\mathrm{L} 1$ retrotransposon open reading frame-1 initiates expression of diverse fusion transcripts and limits retrotransposition. Nucleic Acids Res. 2014;42(7):4546-62.

52. Li J, Akagi K, Hu Y, Trivett AL, Hlynialuk CJ, Swing DA, Volforsky N, Morgan TC, Golubeva Y, Stephens RM, et al. Mouse endogenous retroviruses can trigger premature transcriptional termination at a distance. Genome Res. 2012;22(5):870-84.

53. Franke V, Ganesh S, Karlic R, Malik R, Pasulka J, Horvat F, Kuzman M, Fulka $\mathrm{H}$, Cernohorska M, Urbanova J, et al. Long terminal repeats power evolution of genes and gene expression programs in mammalian oocytes and zygotes. Genome Res. 2017:27(8):1384-94.
54. Fernandez-Gonzalez R, Ramirez MA, Pericuesta E, Calle A, Gutierrez-Adan A. Histone modifications at the blastocyst Axin1(Fu) locus mark the heritability of in vitro culture-induced epigenetic alterations in mice. Biol Reprod. 2010; 83(5):720-7.

55. Luco RF, Pan Q, Tominaga K, Blencowe BJ, Pereira-Smith OM, Misteli T. Regulation of alternative splicing by histone modifications. Science. 2010; 327(5968):996-1000.

56. Naftelberg S, Schor IE, Ast G, Kornblihtt AR. Regulation of alternative splicing through coupling with transcription and chromatin structure. Annu Rev Biochem. 2015;84:165-98.

57. Schor IE, Rascovan N, Pelisch F, Allo M, Kornblihtt AR. Neuronal cell depolarization induces intragenic chromatin modifications affecting NCAM alternative splicing. Proc Natl Acad Sci U S A. 2009;106(11):4325-30.

58. Reed SC. The inheritance and expression of fused, a new mutation in the house Mouse. Genetics. 1937;22(1):1-13.

59. Dickies MM. A new viable yellow mutation in the house mouse. J Hered. 1962;53:84-6.

60. Kurosaki T, Maquat LE. Nonsense-mediated mRNA decay in humans at a glance. J Cell Sci. 2016;129(3):461-7.

61. Conti E, Izaurralde E. Nonsense-mediated mRNA decay: molecular insights and mechanistic variations across species. Curr Opin Cell Biol. 2005;17(3):316-25.

62. Wilkinson MF. A new function for nonsense-mediated mRNA-decay factors. Trends Genet. 2005;21(3):143-8.

63. Yan W. Potential roles of noncoding RNAs in environmental epigenetic transgenerational inheritance. Mol Cell Endocrinol. 2014;398(1-2):24-30.

64. Hisano M, Erkek S, Dessus-Babus S, Ramos L, Stadler MB, Peters AH. Genome-wide chromatin analysis in mature mouse and human spermatozoa. Nat Protoc. 2013;8(12):2449-70.
Ready to submit your research? Choose BMC and benefit from:

- fast, convenient online submission

- thorough peer review by experienced researchers in your field

- rapid publication on acceptance

- support for research data, including large and complex data types

- gold Open Access which fosters wider collaboration and increased citations

- maximum visibility for your research: over $100 \mathrm{M}$ website views per year

At $\mathrm{BMC}$, research is always in progress.

Learn more biomedcentral.com/submissions 